\title{
Effect of incorporating alum in cane juice clarification efficiency and sucrose losses
}

\author{
Benard M. Kimatu ${ }^{\mathrm{a}}$, Abdul K. Faraj ${ }^{\mathrm{a}}$, And Symon M. Mahungu ${ }^{\mathrm{a}}$ \\ ${ }^{a}$ Department of Dairy and Food Science and Technology, Egerton University, P.O. Box 536-20115, Egerton, Kenya \\ ${ }^{*}$ Corresponding author \\ smahungu@yahoo.com \\ TEL: +254-720-961031
}

Received: 18 Mars 2014; Published online: 18 April 2015

\begin{abstract}
The effect of incorporating alum in the clarification stage of raw juice in sugarcane processing on the juice quality and sucrose loss was investigated. Alum was incorporated in both intermediate and hot liming clarification processes of cane juicing. One portion of the cane juice was used for With Pretreatment Treatment (WPT) while the other portion constituted No Pre-treatment (NPT) juice. Alum at levels of $0 \mathrm{mg} \mathrm{L}^{-1}, 50 \mathrm{mg} \mathrm{L}^{-1}, 100 \mathrm{mg} \mathrm{L}^{-1}$ and $150 \mathrm{mg} \mathrm{L}^{-1}$ was incorporated in both intermediate and hot liming clarification processes in each of the two cane juice portions. Sugar concentration (sucrose, glucose and fructose), ${ }^{\circ}$ Brix, $\mathrm{pH}$, colour, settling performance (initial settling rates (ISR), final mud volume $\left(\mathrm{MV}_{\infty}\right)$, and turbidity) and residual aluminium ion concentration were evaluated. Any significant variations $(\mathrm{p}<0.05)$ in these parameters were assessed. The study found significantly lower $(\mathrm{p}<0.05)$ sucrose losses in clarified juice from intermediate liming of WPT after alum treatment than in the rest of the clarified juices. Colour and turbidity in the pre-treated cane juice of intermediate liming was reduced by $36.9 \%$ and $98.1 \%$, respectively at $150 \mathrm{mg} \mathrm{L}^{-1}$ alum level. An initial settling rate of $260 \mathrm{ml} \mathrm{min}^{-1}$ in WPT cane juice of intermediate liming at $150 \mathrm{mg} \mathrm{L}^{-1}$ alum level resulted in the most compact final mud volume of $10.3 \%$. The residual aluminium concentration $\left(0.025\right.$ to $\left.0.048 \mathrm{mg} \mathrm{L}^{-1}\right)$ in alum treated clarified juices was lower than the natural aluminium concentration $\left(0.088 \mathrm{mg} \mathrm{L}^{-1}\right)$ in untreated cane juice. This study showed the potential for the use of alum in cane juice clarification to improve on clarification efficiency and lower sucrose loss.
\end{abstract}

Keywords: Alum; Clarification; Cane juice; Turbidity; Sucrose loss

\section{Introduction}

Conventional technology used in the processing of sugarcane involves extraction of juice from the sugarcane, either by milling or by diffusion, clarification of the raw juice extracted, concentration to syrup and crystallization of the sugar in the syrup (Rein \& Bento, 2006). Sugar losses associated with sugarcane processing can be chemical (degradation under acid or alkaline thermal conditions), microbial or enzymatic, with the latter being mostly limited to sugarcane harvesting, storage and extraction (Eggleston \& Amorim, 2006; Eggleston, Vercellotti, Edye, \& Clarke, 1996). Once extracted, the juice is heated to high temperatures, during which time sugarcane enzymes are denatured and most of the microbes killed, resulting in chemical losses becoming dominant (Saska, Zossi, \& Liu, 2010b; Eggleston \& Amorim, 2006). The major consequence of chemical losses of sucrose at the sugarcane factory is the decrease in sugar yields, and therefore reduction in profits (Eggleston \& Amorim, 2006). The worldwide change from the harvesting of burnt to green (unburnt) 
sugarcane, has resulted in more salts,invert sugars and impurities that are associated with the trash (leaves, tops and soil), being delivered to the factory. These extra impurities, apart from making clarification difficult, catalyse the hydrolysis of sucrose so adversely affecting its recovery and the refining quality of the raw sugar (Eggleston, Monge, \& Pepperman, 2002; Eggleston, Grisham, \& Antoine, 2010, 2014).

One area of potential improvement is in clarification, where the factory should achieve additional removal of colour, turbidity and polysaccharides, and at the same time keep sucrose inversion at a minimum. Work on the potential of cationic aluminium coagulants in cane juice clarification has been ongoing since 2004 (Sugar Research Processing Institute (SPRI, 2006). Preliminary experiments, treating raw cane juice with polyaluminium coagulants on a bench scale, have shown improvement in removal of turbidity, colour, and ash and an increase in $\mathrm{pH}$, when compared to traditional clarification (Godshall, Mckee, Triche, \& Moore, 2006). The analysis of the treated samples showed there was no aluminium carryover in the clarified juice. These results showed the potential for the use of aluminium coagulants in juice clarification. However, the effect of incorporating alum in cane juice clarification on cane juice quality and sucrose inversion losses has not been evaluated. Alum (also soda alum, filter alum, pearl alum or pickle alum) is the name used for aluminium sulphate $\left(\mathrm{Al}_{2}\left(\mathrm{SO}_{4}\right)_{3} .18 \mathrm{H}_{2} \mathrm{O}\right)$ (Ravina \& Moramarco, 1993). When added to water hydrous oxides of aluminium are formed, the simplest of these being aluminium hydroxide $\left(\mathrm{Al}(\mathrm{OH})_{3}\right)$, which is an insoluble precipitate (Pernitsky \& Edzwald, 2006). Several more complex positively charged soluble ions are also formed including: $\mathrm{Al}(\mathrm{OH})^{2+}$, $\mathrm{Al}(\mathrm{OH})_{2}^{+}, \quad \mathrm{Al}_{3}(\mathrm{OH})_{2}^{5+}, \quad \mathrm{Al}_{6}(\mathrm{OH})_{15}^{3+}, \quad \mathrm{Al}_{7}(\mathrm{OH})_{17}^{4+}$ and $\mathrm{Al}_{8}(\mathrm{OH})_{20}^{4+}$ and $\mathrm{Al}_{13} \mathrm{O}_{4}(\mathrm{OH})_{24}^{7+}$ (Jiang \& Graham, 1998; Zouboulis \& Traskas, 2005). The mechanism of coagulation by alum includes both charge neutralization and sweep floc mode. These positively charged complexes can interact strongly with the negative surface charge around the particles that cause turbidity, resulting in destabilization and thus leading to formation of flocs that are denser and able to settle (Muisa, Hoko, \& Chifamba, 2011; Zouboulis \& Traskas, 2005; Degremont, 1991). Simultaneously, aluminium hydrox- ide precipitates will form and grow independently of the colloid population, enmeshing the colloids in the sweep floc mode (Ravina \& Moramarco, 1993). Alkalinity is required for the alum reaction to successively proceed otherwise the $\mathrm{pH}$ would be lowered to the point where soluble aluminium ion $\left(\mathrm{Al}^{3+}\right)$ is formed instead of aluminium hydroxide. Use of polyaluminium in sugar processing is not widespread. However, it has been reported that polyaluminium chloride has been used in Brazil at the level of $400-800 \mathrm{mg} \mathrm{L}^{-1}$ to produce direct consumption white sugar to avoid sulfitation and also in India for the same purpose at the level of $1000 \mathrm{mg} \mathrm{L}^{-1}$ (SPRI, 2006). The current study was aimed at investigating the effect of incorporating alum in cane juice clarification on juice quality and sucrose inversion losses.

\section{Materials and Methods}

\subsection{Factory processing conditions}

Mixed cane juice samples were collected from $\mathrm{Mu}-$ mias Sugar Company (MSC), Kenya. Lime, as a water slurry (average Baume $\sim 15^{\circ}$ ) is automatically dosed into the extracted cane juice to a target $\mathrm{pH}$ of 7.2 . The limed juice is passed through primary and secondary heaters where it is superheated under pressure $(113 \mathrm{kPa}$ abs $)$ to $103{ }^{\circ} \mathrm{C}$. The heated limed juice is then released into an open vessel (Flush tank) where it boils instantaneously releasing air bubbles that would otherwise be trapped in the floc and cause settling difficulties. The flushed juice is dosed with anionic polyelectrolyte flocculant (INDOFLOC ${ }^{\circledR}$ ) at $3 \mathrm{mg} \mathrm{L}^{-1}$ before entering a continuous clarifier maintained at $96{ }^{\circ} \mathrm{C}$. The clarifier residence time is 45 minutes. The clarified juice is pumped to the evaporator station while the mud is recycled to the diffuser and eventually leaves with the bagasse.

\subsection{Cane juice collection and treatment}

Mixed cane juice samples each of sixteen litres were taken from the diffuser at 2-hour intervals over a 6 hour sampling period. The sampling period was repeated three times over a period of three months to cover cane variety, environmental and 
process parameter variations. Each sample was split into two halves of eight litres. The first half was used for With Pre-treatment (WPT) which involved preheating and incubation, while the other half was used for the No Pre-treatment (NPT) analysis. The protocol followed is presented in Figure 1.

\section{Cane juice with pre-treatment}

The eight litres of cane juice were divided into two equal parts. One part was preheated to 90 ${ }^{\circ} \mathrm{C}$ and mixed with the other half before incubating at ambient temperature for 8 minutes. After incubation the juice was again split into two portions; one half was used for the intermediate liming process while the other half was used for the hot liming process. In the intermediate liming process, lime was added as a water slurry (average Baume $\sim 15^{\circ}$ ) with constant stirring to a target juice $\mathrm{pH}$ of 7.2. The limed juice was heated to boiling before subdividing it into four equal portions. Four alum levels $\left(0 \mathrm{mg} \mathrm{L}{ }^{-1}, 50 \mathrm{mg} \mathrm{L}^{-1}\right.$, $100 \mathrm{mg} \mathrm{L}^{-1}$, and $150 \mathrm{mg} \mathrm{L}^{-1}$ ) were added to each portion and mixed thoroughly. Anionic polyelectrolyte flocculant (INDOFLOC ${ }^{\circledR}$ ) at $3 \mathrm{mg} \mathrm{L}^{-1}$ was added to each portion and stirred thoroughly. A sample of $300 \mathrm{ml}$ was drawn from each portion for determination of settling rates and mud volumes. The remaining juice in each portion was allowed to clarify in an incubator at $96{ }^{\circ} \mathrm{C}$ for 45 minutes. For settling rates and mud volume determinations, the $300 \mathrm{ml}$ was poured into a settling tube $(5 \mathrm{~cm} \mathrm{x}$ $34 \mathrm{~cm}$ ) in a water bath and stoppered. The water bath was maintained at $96^{\circ} \mathrm{C}$. Samples for analysis were drawn from the mixed juice(MJ), juice after incubation (AFTINCB), heated limed juice (LJ) and clarified juice (CJ) from the four alum treated portions $\left(\mathrm{CJ}_{0}, \mathrm{CJ}_{50}, \mathrm{CJ}_{100}\right.$ and $\left.\mathrm{CJ}_{150}\right)$.For hot liming process, the preheated and incubated juice was first heated to boiling before liming to a target $\mathrm{pH}$ of 7.2. The limed juice was subdivided into four equal portions which were treated like the intermediate liming process before drawing samples for settling rate and mud volume measurements from each portion. Samples for analysis were drawn from heated limed juice (LJ) and clarified juices from the four alum treated portions $\left(\mathrm{CJ}_{0}, \mathrm{CJ}_{50}, \mathrm{CJ}_{100}\right.$ and $\left.\mathrm{CJ}_{150}\right)$. Each sample in both liming processes was collected in a $250 \mathrm{ml}$ flask. Exactly $25 \mathrm{ml}$ of this sample was transferred into a $50 \mathrm{ml}$ flask and sodium azide $(0.02 \%)$ added to reduce/prevent chemical and microbial degradation of sucrose. The sodium azide-treated samples were stored in dry ice at $\sim-78^{\circ} \mathrm{C}$. Glucose, fructose and sucrose concentrations were measured in juice from the stored samples. After removal of 25 $\mathrm{ml}$ sugar cane juice from each sample, the remaining juice was used for colour, turbidity, ${ }^{\circ}$ Brix and $\mathrm{pH}$ determinations.

\section{Cane juice without pre-treatment}

The other eight litres of cane juice were split into two portions. Half was used for the intermediate liming process while the other half was used for the hot liming process. The intermediate and hot liming processes were carried out as described for cane juice with pre-treatment. Samples for analysis from the intermediate liming process were drawn from heated limed juice (LJ) and clarified juices from the four alum treated portions $\left(\mathrm{CJ}_{0}\right.$, $\mathrm{CJ}_{50}, \mathrm{CJ}_{100}$ and $\mathrm{CJ}_{150}$ ). A similar protocol was followed for the samples from the hot liming process. Each sample from the two liming processes was collected in a $250 \mathrm{ml}$ flask. The samples were then treated exactly as those from the cane juice with pre-treatment.

\subsection{Determination of sucrose, glucose and fructose by HPLC}

The determination of sucrose, fructose and glucose in cane juices was done by isocratic HPLC analysis based on the Official International Commission of Uniform Methods of Sugar Analysis (ICUMSA) method GS7/4/8-23 (ICUMSA, 2002). Ten grams of the cane juice were diluted using a small quantity of distilled water in a $100 \mathrm{ml}$ volumetric flask. The volumetric flask was made up to the mark with distilled water and the solution mixed well by shaking. At the same time three working mixed standards each containing sucrose (Fisher Scientific, Leicestershire-UK), fructose (Duchefa Biochemie, The Netherlands) and glucose (Prolabo, Paris-France) were prepared by dissolving in distilled water the following quantities of the sugars: standard 1 (sucrose $0.2521 \mathrm{~g}$, fructose 0.2509 $\mathrm{g}$, glucose $0.2528 \mathrm{~g}$ ), standard 2 (sucrose 0.5040 
$64 \mid$ Kimatu et al.

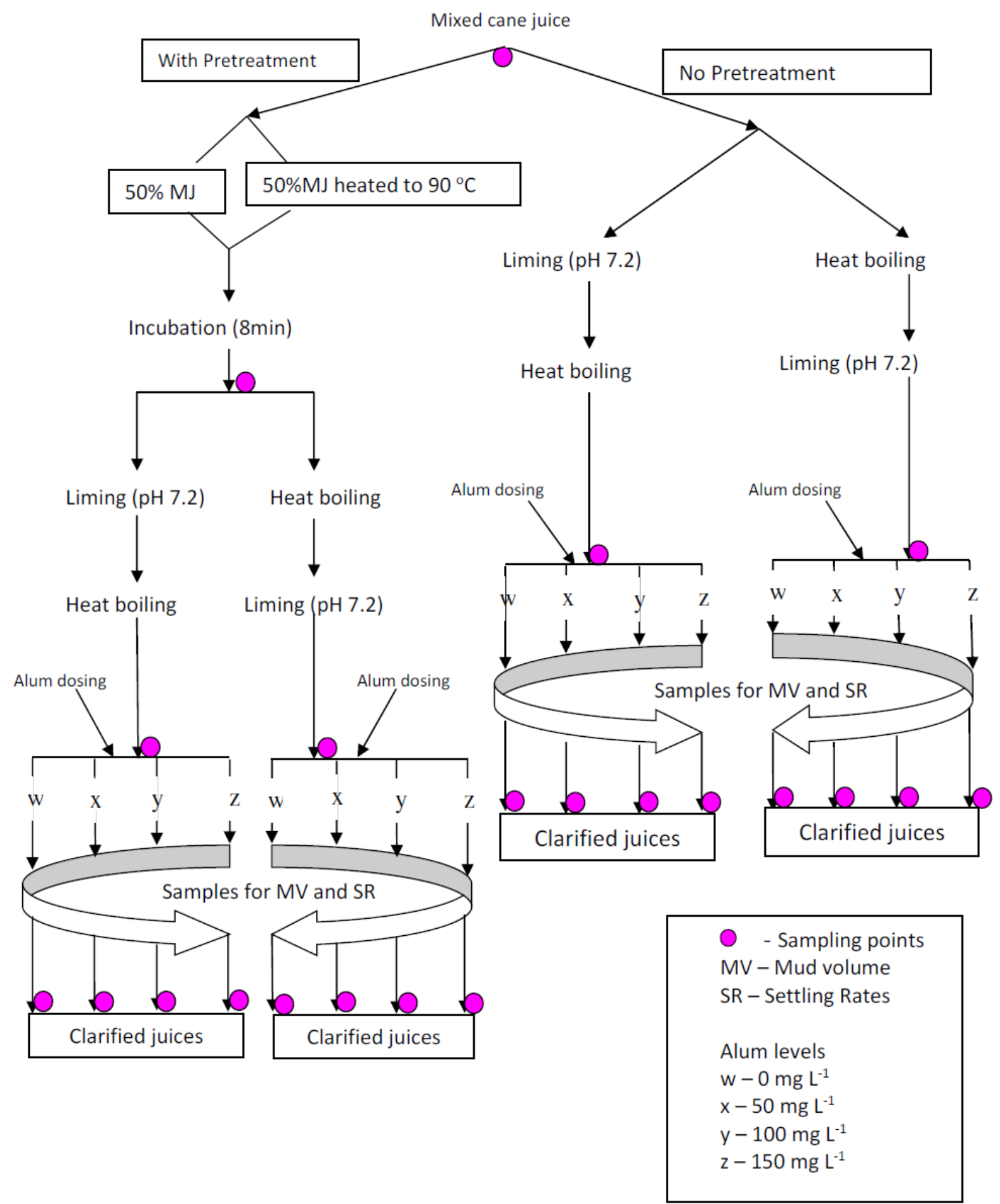

Figure 1: Mixed cane juice treatment protocol 
$\mathrm{g}$, fructose $0.5041 \mathrm{~g}$, glucose $0.5098 \mathrm{~g}$ ) and standard 3 (sucrose $0.7563 \mathrm{~g}$, fructose $0.7554 \mathrm{~g}$, glucose $0.7518 \mathrm{~g}$ ) in a $100 \mathrm{ml}$ volumetric flask and made up to the mark. The samples and the standards were then filtered into $2.5 \mathrm{ml}$ vials using a syringe filter and a membrane filter of $0.45 \mu \mathrm{m}$ pore size. Isocratic analyses for the sugars was done using a Shimadzu liquid chromatograph system SCL-10A (Tokyo, Japan) equipped with a pump, LC-10AS, thermostatically controlled Shimadzu column oven (CTO-10A) and a Shimadzu Refractive Index Detector (RID-6A). The analyses were done on a reversed phase amino column $(\mathrm{Nu}-$ cleodur Amino-RP, 4.6x250 mm, $5 \mu \mathrm{m}$, Machery
Nigel, Germany). The mobile phase used was acetonitrile:water $(75: 25 \mathrm{v} / \mathrm{v})$. Chromatographic conditions used were; flow rate $0.9 \mathrm{ml} \mathrm{min}^{-1}$., column temperature of $35{ }^{\circ} \mathrm{C}$ and a head pressure of $23-$ $31 \mathrm{kgf} \mathrm{cm}^{-2}$. A volume of $20 \mu \mathrm{L}$ of the working standards or the diluted samples was injected and $1 \mu \mathrm{L}$ loaded into the HPLC system by a sampling loop. The peak areas obtained were plotted on a Shimadzu C-R7A PLUS CHROMATOPAC data integrator. Using the working standards, peak areas, average response factors ( $\mathrm{g}$ unit area $^{-1}$ ) for each sugar was calculated.

Each sugar concentration in the samples was calculated as follows:

$$
\text { Sugar conc. }(\%)=\frac{[\text { response factor } \times \text { sugar peak area }]}{\text { sample weight }} \times 100
$$

Percent sucrose losses were calculated using the 1985): following formula by (Schaffler, Muzzell, \& Schorn,

$$
\text { Sucrose lost }=\frac{\left[\left(\frac{G l u}{o_{\text {Brix }}}\right)_{\text {out }}-\left(\frac{G l u}{o_{\text {Brix }}}\right)_{\text {in }}\right]}{\left(\frac{\text { Suc }}{o_{\text {Brix }}}\right)_{\text {in }} \times M W_{G l u}} \times M W_{\text {suc }} \times 100
$$

Where: $M W=$ molecular weight

Suc $=$ sucrose

Glu $=$ glucose

${ }^{\circ}$ Brix $=$ percent dissolved solids

\section{$2.4 \mathrm{pH}$ measurement}

The $\mathrm{pH}$ of the sample juices were measured and corrected to $25{ }^{\circ} \mathrm{C}$ using a Control Dynamics $\mathrm{pH}$ Meter (Model: APX 175E/C C.D. Instrumentation PVT Ltd, Bangalore, India) calibrated using pH buffers pH 4 and pH 7.

\subsection{Determination of ${ }^{\circ}$ Brix (\% Refractometric Dissolved Solids)}

The mean ${ }^{\circ}$ Brix (corrected to $20{ }^{\circ} \mathrm{C}$ ) of triplicate samples was measured using a temperaturecontrolled refractometer accurate to $\pm 0.01{ }^{\circ}$ Brix (Model GPR 12-70X. Index Instruments Ltd, England).

\subsection{Determination of cane juice colour and turbidity}

Colour and turbidity of the juice were measured as the absorbance at $420 \mathrm{~nm}$ and calculated according to the official ICUMSA method GS2/3- 
$66 \mid$ Kimatu et al.

10 (ICUMSA, 2005). Samples (5 g) were diluted in triethanolamine / hydrochloric $(\mathrm{TEA} / \mathrm{HCl})$ acid buffer solution $(\mathrm{pH} 7)$ and filtered under vacuum through a $0.45 \mu \mathrm{m}$ filter in to a clean dry conical flask to remove turbidity. The filtrate was de-aerated by immersing the conical flask containing the filtrate in an ultrasonic bath for 3 minutes. Absorbancy $\left(\mathrm{A}_{s}\right)$ of the de-aerated filtrate was measured at $420 \mathrm{~nm}$ using filtered and de-aerated TEA/HCl buffer solution as the standard for zero colour/turbidity. The refractometric dry substance (RDS) of the sample was also measured as described in ICUMSA method GS4-13. ICUMSA colour units were calculated as follows:

$$
I C U M S A_{\text {colour }}=\frac{10_{8} \times A_{s}}{b \times(\text { corrected } R D S) \times \rho} I U_{7.0}
$$

Where: $A_{s}=$ Absorbancy at $420 \mathrm{~nm}$ $b=$ length $(\mathrm{cm})$ of the absorbing path $\rho=$ density of test solution $\left(\mathrm{kgm}^{-3}\right)$.

\subsection{Determination of settling rates and mud volumes}

Settling rates and mud volume measurements and calculations were based on the method of Lionnet and Ravn (1976), with modifications by Eggleston, Monge, \& Pepperman (2002). The samples were heated to the clarifier temperature $\left(96{ }^{\circ} \mathrm{C}\right)$ with constant stirring before pouring into a settling tube. The settling tube was mounted in a water bath maintained at the clarifier temperature. Each sample was poured into a settling tube to a volume of $300 \mathrm{ml}$ and stoppered immediately and mud levels taken between $0.0-18.0$ minutes. Mud height (ml) was plotted against time. The initial settling rate (ISR) in ml per minute was graphically determined from the initial linear slope. Mud volume after 18 minutes $\left(\mathrm{MV}_{18}\right)$ was read directly. The final equilibrium mud volume $\left(\mathrm{MV}_{\infty}\right)$ or final height of the mud after infinite time was obtained from the intercept on a plot of MV percent against $1 / \mathrm{t}$, where $t$ is time in minutes.

\subsection{Determination of residual aluminium ions}

Aluminium ions were determined in the clarified juice using the atomic absorption spectroscopy technique (AOAC, 2000). Clarified juice samples were filtered using a Millipore $0.45 \mu \mathrm{m}$ cellulose acetate filters. An Atomic Absorption Spectrophotometer, (Shimadzu, Model AA-6300, Tokyo-Japan) with nitrous oxide-acetylene flame was used. Standards of known concentrations and blanks were used for calibration. Aluminium ions were measured by atomic absorption as the ions absorbed radiation from element specific hollow cathode lamp set at a wave length of $309.3 \mathrm{~nm}$. The absorbencies obtained were used to estimate the concentrations of the metal ions in the samples from the standard curve.

\subsection{Statistical analysis}

Data analysis was done using Statistical Analysis Software, PC-SAS 9.1 (SAS, 2002-2003). Univariate analysis of variance and General Linear Model procedure were carried out to determine the effect of pre-treatment, liming process and alum on clarified juice quality and sucrose loss. Treatment means separation was done by Fisher's Least Significant Difference at $\alpha=0.05$.

\section{Results and Discussion}

\section{1 ${ }^{\circ}$ Brix and sugar concentrations}

The mean ${ }^{\circ}$ Brix and mean sugar concentrations in NPT alum treated cane juice for both intermediate and hot liming processes are presented in Table 1 . In the NPT sample, ${ }^{\circ}$ Brix deceased significantly $(\mathrm{p}<0.05)$ from $15.35 \pm 0.32$ in theMJ to $14.88 \pm 0.51$ in the LJ for the hot liming process. This coincides with a significant decrease in the mean concentration of the invert sugars from MJ to LJ. In the intermediate liming, the decrease in ${ }^{\circ}$ Brix from $15.35 \pm 0.32$ in MJ to $15.04 \pm 0.26$ in the LJ was not significant $(\mathrm{p}>0.05)$. The mean concentration of the invert sugar for both the intermediate and hot liming processes decreased significantly $(\mathrm{p}<0.05)$ upon liming the MJ. In the intermediate liming process, glucose decreased from 
$1.82 \pm 0.07$ in the MJ to $1.62 \pm 0.12$ in the LJ while fructose decreased from $1.74 \pm 0.07$ in the MJ to $1.57 \pm 0.07$ in the LJ (Table 2). In the hot liming process, the decrease in glucose and fructose from the MJ to the LJ was $1.82 \pm 0.07$ to $1.59 \pm 0.12$ and $1.74 \pm 0.07$ to $1.48 \pm 0.16$, respectively. The decrease in the invert sugar concentrations was considered to be due to alkaline degradation of these sugars, a reaction that increases with temperature and retention time (Eggleston, Clarke, \& Pepperman, 1999; Eggleston, 2000; Eggleston, Monge, \& Ogier, 2002) leading to colour formation. A similar trend in invert sugar concentrations was reported by Eggleston, Monge, and Pepperman (2002) while comparing cold and intermediate liming processes and Eggleston, Monge, and Ogier (2002) while assessing factory performance of cold, intermediate and hot liming clarification processes. The decrease in ${ }^{\circ}$ Brix from MJ to LJ could be further evidence to this. It was observed that in all the samples, lower fructose concentrations than glucose concentrations were recorded. The increase in invert sugar concentrations from LJ to CJ, the first degradation products of inversion, is an indicator of acid inversion of sucrose in sugarcane factories (Godshall, Clarke, \& Dooley, 1991). This is because in comparison to the high concentrations of sucrose, they occur at lower and therefore measurable concentrations and changes in their concentrations are more easily detected (Schaffler et al., 1985). Although sucrose inverts to equal amounts of glucose and fructose, fructose is more labile than glucose in acid conditions (Schaffler et al., 1985) making it an inaccurate measurement of inversion. It is on this basis that Schaffler and co-workers (1985) demonstrated that glucose and sucrose referenced to ${ }^{\circ}$ Brix can be used to accurately calculate the percent sucrose loss and their calculation formula (Equation 2) was used in this study. In the WPT sample where the cane juice was preheated and incubated before liming, there was an insignificant decrease $(\mathrm{p}>0.05)$ in ${ }^{\circ}$ Brix from the MJ to the LJ in both liming processes (Table 2). The preheating and incubation of the MJ led to a significant decrease $(\mathrm{p}<0.05)$ in invert sugar concentration from $1.82 \pm 0.07$ in the MJ to $1.61 \pm 0.12$ in the juice after incubation (AFTINCB) for glucose and from $1.74 \pm 0.07$ in the MJ to $1.49 \pm 0.11$ in the AFTINCB for fructose. After liming the incubated juice, the invert sugars again decreased significantly $(\mathrm{p}<0.05)$ in the intermediate liming. In hot liming, there was a significant decrease $(\mathrm{p}<0.05)$ in the invert sugar concentrations upon liming the AFTINCB. Acid inversion of sucrose in sugarcane factories is easily indicated by an increase in glucose and fructose, the first products of inversion (Godshall et al., 1991). According to Eggleston, Monge, and Pepperman (2002), a possible problem associated with preheating of acidic mixed juice as is the case with the WPT, is sucrose inversion. However, as observed in Table 2 there was a mean decrease in invert sugar concentrations from the MJ to the AFTINCB samples. The one and a half minute heating time probably minimised inversion and could be that some invert sugars may have been removed with heatinduced precipitation of colloids, macromolecules (starch, dextran polysaccharides and proteins) and colour (de Armas, Martinez, Vicente, \& Legaz, 1999; Saska, Zossi, \& Liu, 2010a). The decrease in ${ }^{\circ}$ Brix from the MJ to the AFTINCB could be further evidence of this. In both liming processes, there was a decrease in invert sugar concentrations from the AFTINCB to the LJ (Table 2). This was associated with the alkaline degradation of these sugars, a reaction that is a function of temperature and time (Eggleston, Monge, \& Ogier, 2002; Eggleston, 2000; Eggleston et al., 1999). In the clarified juices, higher increases in glucose concentrations were recorded in the hot liming process than in intermediate liming process, a pointer to higher sucrose losses in the hot liming process.

The sucrose loss during the clarification in the NPT and the WPT for both liming processes is summarised in Table 3. There was no significant ( $p>0.05)$ sucrose loss differences in the juices clarified without alum addition. However, the sucrose loss after clarification in the WPT intermediate liming was significantly lower for each alum level than in the rest of the clarified juices. Alum addition in each of the liming processes did not significantly $(p>0.05)$ affect the sucrose loss except in the WPT intermediate liming where the loss with the addition of alum at $50 \mathrm{mg}, 100 \mathrm{mg}$ and $150 \mathrm{mg}$ was significantly lower than the control. A study by Eggleston et al. (2014) indicated that the higher $\mathrm{pH}$ of clarified juices after saccharate liming than after adding milk of lime led to lower sucrose loss due to acid inversion of sucrose across the clarifier. Results from this study strongly suggest that 
$68 \mid$ Kimatu et al.

intermediate lime clarification of WPT cane juice with addition of alum could be an important tool for sugar processors to reduce expensive sucrose losses.

\subsection{Colour and $\mathrm{pH}$}

Colour in sugar process streams consists of a complex mixture of compounds that originate naturally from the cane plant or produced during processing in the factory and its appearance in raw sugar plays a key role in the marketing strategy of sugar industries worldwide (Nguyen \& Doherty, 2012a, 2012b; Davis, 2001). The colour and pH in the NPT cane juice for both intermediate and hot liming processes are presented in Table 4. In the NPT cane juice, the $\mathrm{pH}$ of the clarified juices in intermediate liming were not significantly different $(\mathrm{p}<0.05)$ and ranged from $6.43 \pm 0.19$ in $\mathrm{CJ}_{0}$ to $6.54 \pm 0.17$ in $\mathrm{CJ}_{150}$. The $\mathrm{pH}$ of the clarified juices in hot liming were also not significantly different $(\mathrm{p}<0.05)$ and ranged from $6.40 \pm 0.11$ in $\mathrm{CJ}_{0}$ to $6.51 \pm 0.15$ in $\mathrm{CJ}_{150}$. In both liming processes, the $\mathrm{pH}$ reduced significantly $(\mathrm{p}<0.05)$ from the limed juice to the clarified juices. This drop in $\mathrm{pH}$ upon clarification of the limed juice is as a result of the precipitation of lime salts during settling of the mud (Eggleston, Monge, \& Pepperman, 2002; Eggleston, Monge, \& Ogier, 2002) and the inversion of sucrose with associated production of acids (Eggleston et al., 2010) could also have contributed to this. Similarly, in the WPT cane juice, the $\mathrm{pH}$ of the clarified juices in intermediate liming and hot liming (Table4) were not significantly different $(\mathrm{p}<0.05)$. However, there was a significant $(\mathrm{p}<0.05)$ drop in $\mathrm{pH}$ from limed juice to clarified juices in both liming processes.

Colour formation is an indicator of sugar degradation and subsequently the quality of the raw sugar (Eggleston \& Monge, 2005). In the NPT cane juice, colour significantly increased $(\mathrm{p}<0.05)$ upon liming the MJ in both the intermediate and hot liming processes (Table 4). In the intermediate liming, there was a $12.4 \%$ colour increase from MJ to LJ while in the hot liming the colour increase from the MJ to the LJ was $13.9 \%$ (Table 4). The colour formation upon liming of the MJ was due to the alkaline degradation of the invert sugars, a reaction that is relatively fast and is a func- tion of temperature and retention time (Eggleston, Monge, \& Ogier, 2002; Eggleston, 2000; Eggleston et al., 1999). The higher colour formation in hot liming could have been due to the heating of the acidic MJ before liming. When cane juice is heated under moderate acid conditions (between $\mathrm{pH} 5.5$ and 6.8), colour is formed from the acid degradation of sucrose and invert sugars (Eggleston \& Amorim, 2006). On settling the limed juice, colour was significantly $(\mathrm{p}<0.05)$ removed in the clarified juices of both liming processes. The highest colour reduction of $33.6 \%$ in intermediate liming was recorded in $\mathrm{CJ}_{150}$ which was significantly higher than the colour reduction of $24 \%$ in $\mathrm{CJ}_{0}$ (Table 4). In hot liming, a colour reduction of $30.6 \%$ and $29.4 \%$ was observed in $\mathrm{CJ}_{150}$ and $\mathrm{CJ}_{100}$, respectively and these were not significantly different (Table 4). The least colour removal $(23.1 \%)$ was recorded in $\mathrm{CJ}_{0}$. It can be concluded from these results that addition of alum at $150 \mathrm{mgL}^{-1}$ of cane juice in intermediate liming gave clarified juice with the highest colour removal.

In the WPT cane juice, pre-heating and incubating the mixed juice led to increased colour removal in the clarified juices for both intermediate and hot liming processes. By pre-heating and incubating the MJ, juice colour was significantly removed $(\mathrm{p}<0.05)$ from $13271 \mathrm{IU}$ in MJ to 11041 IU in AFTINCB. The colour removal preceding the incubation is considered to be heat-induced and is associated with the precipitation of colloids and macromolecules, including starch, dextran polysaccharides and proteins (de Armas et al., 1999; Saska et al., 2010a). Eggleston, Monge, and Pepperman (2002) reported a 29\% colour removal in intermediate liming from the mixed juice when $30 \%$ of the mixed juice was pre-heated before incubation. However, this colour removal was offset by colour formation on liming the juice. On liming the AFTINCB, significant colour formation was recorded in both liming processes (Table 5). In intermediate liming, colour increased by $8.4 \%$ from AFTINCB to LJ compared to an increase of $11.9 \%$ in hot liming from AFTINCB to LJ (Table 5). This colour formation was caused by alkaline degradation of invert sugars, an observation made earlier by Eggleston (2000) and Eggleston et al. (1999). There was significant $(\mathrm{p}<0.05)$ colour removal upon clarifying the limed juice in both liming processes. In intermediate liming, significantly 
Alum Effect in Cane Juice Clarification |69

Table 1: ${ }^{\circ}$ Brix and ${ }^{\omega}$ Sugar concentrations (mean $\pm \mathrm{SD}$ ) for No Pre-treatment cane juices

\begin{tabular}{lcccc}
\hline \multicolumn{5}{c}{ Intermediate Liming } \\
\hline Sample & ${ }^{\circ}$ Brix & Sucrose $/{ }^{\circ}$ Brix & Glucose $/{ }^{\circ}$ Brix & Fructose $/{ }^{\circ}$ Brix \\
\hline Mixed juice & $15.35 \pm 0.32^{a}$ & $87.82 \pm 2.78^{a}$ & $1.82 \pm 0.07^{b}$ & $1.74 \pm 0.07^{b}$ \\
Limed juice & $15.04 \pm 0.26^{a b}$ & $87.71 \pm 2.36^{a}$ & $1.62 \pm 0.12^{c}$ & $1.57 \pm 0.07^{c}$ \\
$\mathrm{CJ}_{0}$ & $14.98 \pm 0.27^{a b c}$ & $87.22 \pm 1.73^{a}$ & $2.23 \pm 0.10^{a}$ & $1.98 \pm 0.13^{a}$ \\
$\mathrm{CJ}_{50}$ & $15.19 \pm 0.45^{a b}$ & $86.16 \pm 2.68^{a}$ & $2.22 \pm 0.11^{a}$ & $2.07 \pm 0.12^{a}$ \\
$\mathrm{CJ}_{100}$ & $14.88 \pm 0.39^{b c}$ & $88.21 \pm 2.53^{a}$ & $2.20 \pm 0.12^{a}$ & $2.02 \pm 0.12^{a}$ \\
$\mathrm{CJ}_{150}$ & $14.68 \pm 0.69^{c}$ & $88.29 \pm 4.23^{a}$ & $2.21 \pm 0.10^{a}$ & $2.00 \pm 0.13^{a}$ \\
& \multicolumn{4}{c}{} \\
\hline \multicolumn{5}{c}{ Hot Liming } \\
\hline TMJ $_{\text {Limed juice }} 15.35 \pm 0.32^{a}$ & $87.82 \pm 2.78^{a b}$ & $1.82 \pm 0.07^{b}$ & $1.74 \pm 0.07^{b}$ \\
$\mathrm{CJ}_{0}$ & $14.97 \pm 0.51^{b c}$ & $89.01 \pm 4.22^{a}$ & $1.59 \pm 0.12^{c}$ & $1.48 \pm 0.16^{c}$ \\
$\mathrm{CJ}_{50}$ & $87.70 \pm 2.05^{a b}$ & $2.23 \pm 0.12^{a}$ & $2.07 \pm 0.11^{a}$ \\
$\mathrm{CJ}_{100}$ & $15.03 \pm 0.41^{a b}$ & $87.28 \pm 2.73^{a b}$ & $2.22 \pm 0.13^{a}$ & $2.04 \pm 0.13^{a}$ \\
$\mathrm{CJ}_{150}$ & $14.61 \pm 0.53^{c}$ & $89.82 \pm 2.98^{a}$ & $2.21 \pm 0.10^{a}$ & $2.03 \pm 0.10^{a}$ \\
& $15.13 \pm 0.42^{a b}$ & $86.12 \pm 2.78^{b}$ & $2.20 \pm 0.08^{a}$ & $2.10 \pm 0.11^{a}$ \\
\hline
\end{tabular}

Means in the same column followed by the same superscript are not significantly different at $\mathrm{p}<0.05 . \mathrm{n}=9$. ${ }^{\omega}$ Sugar concentration is percent sugar (measured by HPLC) $/{ }^{\circ}$ Brix; $\mathrm{CJ}_{0}, \mathrm{CJ}_{50}, \mathrm{CJ}_{100}$, and $\mathrm{CJ}_{150}=$ clarified juice after treatment with $0,50,100$ and $150 \mathrm{mg}$ of alum, respectively.

$(\mathrm{p}<0.05)$ higher colour removal was observed in $\mathrm{CJ}_{50}, \mathrm{CJ}_{100}$ and $\mathrm{CJ}_{150}$ than in $\mathrm{CJ}_{0}$. Similarly in hot liming, $\mathrm{CJ}_{0}$ had significantly lower colour removal than in $\mathrm{CJ}_{50}, \mathrm{CJ}_{50}, \mathrm{CJ}_{100}$ and $\mathrm{CJ}_{150}$.

\subsection{Settling performance}

\section{Initial settling rate}

Mud settling during clarification is important because any carryover of slow settling particles causes difficulties later in the process and in subsequent processes such as refining (Schoonees-Muir \& Gwegwe, 2008). Mud volume is important as too high a volume puts an extra burden on the mud filter station and there is a greater possibility of having unwanted carryover of mud into the evaporator station (Eggleston et al., 2014) Differences in settling performance in the various limed cane juices were assessed in terms of initial settling rate (ISR) and final mud volume $\left(\mathrm{MV}_{\infty}\right)$. The initial settling rate (ISR) and final mud volume $\left(\mathrm{MV}_{\infty}\right)$ results for NPT and WPT are presented in Table 6 . In the NPT intermediate liming, ISRs ranged from $203 \mathrm{ml} \mathrm{min}-1$ in $\mathrm{CJ}_{0}$ to $256 \mathrm{ml} \mathrm{min}{ }^{-1}$ in $\mathrm{CJ}_{150}$. The ISRs for $\mathrm{CJ}_{50}, \mathrm{CJ}_{100}$ and $\mathrm{CJ}_{150}$ did not differ significantly $(\mathrm{p}<0.05)$ from each other but were significantly different from the ISR for $\mathrm{CJ}_{0}$. In NPT hot liming, the ISRs ranged from 196 $\mathrm{ml} \mathrm{min}{ }^{-1}$ in $\mathrm{CJ}_{0}$ to $240 \mathrm{ml} \mathrm{min-}{ }^{-1}$ in $\mathrm{CJ}_{150}$. The ISR for $\mathrm{CJ}_{0}$ differed significantly $(\mathrm{p}<0.05)$ from the ISR for $\mathrm{CJ}_{50}, \mathrm{CJ}_{100}$ and $\mathrm{CJ}_{150}$ which did not differ significantly from each other. Generally, lower ISRs were observed in hot liming process than in intermediate liming process for the NPT. In the WPT, ISRs in intermediate liming process ranged from $212 \mathrm{ml} \mathrm{min}^{-1}$ in $\mathrm{CJ}_{0}$ to $260 \mathrm{ml} \mathrm{min}{ }^{-1}$ in $\mathrm{CJ}_{150}$. The ISRs for $\mathrm{CJ}_{50}, \mathrm{CJ}_{100}$ and $\mathrm{CJ}_{150}$ did not differ significantly $(\mathrm{p}<0.05)$ from each other. The lowest ISR (208 ml min-1) in WPT for hot liming was recorded in $\mathrm{CJ}_{0}$ and differed significantly $(\mathrm{p}<0.05)$ from $\mathrm{CJ}_{50}, \mathrm{CJ}_{50}$ and $\mathrm{CJ}_{150}$. Generally, lower ISRs were observed in hot liming process than in intermediate liming process for the WPT. The higher settling performance in the alum dosed cane juices could be explained by the fact that when the flocculant is combined with the aluminium coagulant, the suspended material is aggregated into larger and heavier particles that settle faster (Anon, 2005). 
70 | Kimatu et al.

Table 2: ${ }^{\circ}$ Brix and ${ }^{\omega}$ Sugar cconcentrations (mean $\pm \mathrm{SD}$ ) for With Pre-treatment cane juices

\begin{tabular}{lcccc}
\hline \multicolumn{5}{c}{ Intermediate Liming } \\
\hline Sample & ${ }^{\circ}$ Brix & Sucrose $/{ }^{\circ}$ Brix & Glucose $/{ }^{\circ}$ Brix & Fructose $/{ }^{\circ}$ Brix \\
\hline TMJ & $15.35 \pm 0.32^{c d}$ & $87.82 \pm 2.78^{a}$ & $1.82 \pm 0.07^{b}$ & $1.74 \pm 0.07^{b}$ \\
AFTINCB & $15.01 \pm 0.14^{e}$ & $86.78 \pm 1.56^{a b}$ & $1.61 \pm 0.12^{c}$ & $1.49 \pm 0.11^{c}$ \\
Limed juice & $15.17 \pm 0.26^{d e}$ & $86.73 \pm 1.84^{a b}$ & $1.49 \pm 0.08^{d}$ & $1.36 \pm 0.09^{d}$ \\
CJ $_{0}$ & $15.43 \pm 0.20^{b c}$ & $86.15 \pm 1.48^{b}$ & $2.09 \pm 0.13^{a}$ & $1.90 \pm 0.09^{a}$ \\
CJ $_{50}$ & $15.65 \pm 0.14^{a b}$ & $86.14 \pm 1.65^{a b}$ & $2.02 \pm 0.11^{a}$ & $1.82 \pm 0.08^{a b}$ \\
CJ $_{100}$ & $15.42 \pm 0.31^{b c}$ & $85.99 \pm 1.56^{b}$ & $2.03 \pm 0.17^{a}$ & $1.87 \pm 0.10^{a}$ \\
CJ $_{150}$ & $15.70 \pm 0.16^{a}$ & $86.57 \pm 1.02^{a b}$ & $2.04 \pm 0.11^{a}$ & $1.84 \pm 0.09^{a}$ \\
& & & \\
\hline \multicolumn{5}{c}{ Hot Liming } \\
\hline TMJ $^{\text {AFTINCB }}$ & $15.35 \pm 0.32^{b c}$ & $87.82 \pm 2.78^{a}$ & $1.82 \pm 0.07^{b}$ & $1.74 \pm 0.07^{b}$ \\
Limed juice CJ $_{0}$ & $15.31 \pm 0.14^{c}$ & $86.78 \pm 1.56^{a b}$ & $1.61 \pm 0.12^{c}$ & $1.49 \pm 0.11^{c}$ \\
CJ $_{50}$ & $15.65 \pm 0.26^{a}$ & $84.39 \pm 0.46^{a b}$ & $1.52 \pm 0.13^{c}$ & $1.42 \pm 0.14^{c}$ \\
CJ $_{100}$ & $15.62 \pm 0.23^{a}$ & $84.26 \pm 1.40^{c}$ & $2.13 \pm 0.06^{a}$ & $1.86 \pm 0.08^{a}$ \\
CJ $_{150}$ & $15.35 \pm 0.35^{b c}$ & $85.27 \pm 1.78^{b c}$ & $2.11 \pm 0.12^{a}$ & $1.83 \pm 0.09^{a b}$ \\
& $15.54 \pm 0.31^{a b}$ & $84.58 \pm 1.54^{c}$ & $2.11 \pm 0.09^{a}$ & $1.82 \pm 0.11^{a b}$ \\
& & & & \\
\hline
\end{tabular}

Means in the same column followed by the same superscript are not significantly different at $\mathrm{p}<0.05$. $\mathrm{n}=9$. ${ }^{\omega} \mathrm{Sugar}$ concentration is percent sugar (measured by HPLC) $/{ }^{\circ}$ Brix; $\mathrm{CJ}_{0}, \mathrm{CJ}_{50}, \mathrm{CJ}_{100}$, and $\mathrm{CJ}_{150}=$ clarified juice after treatment with $0,50,100$ and $150 \mathrm{mg}$ of alum, respectively.

Table 3: Sucrose loss (mean $\pm \mathrm{SD}$ ) (\%) after clarification for the various alum levels

\begin{tabular}{llcccc}
\hline & & \multicolumn{4}{c}{ Alum levels } \\
\cline { 3 - 5 } & Treatment & $0 \mathrm{mg}$ & $50 \mathrm{mg}$ & $100 \mathrm{mg}$ & $150 \mathrm{mg}$ \\
\hline \multirow{2}{*}{ NPT } & Intermediate liming & $1.32 \pm 0.03^{a A}$ & $1.30 \pm 0.02^{a A}$ & $1.26 \pm 0.02^{a A}$ & $1.27 \pm 0.03^{a A}$ \\
& Hot liming & $1.37 \pm 0.06^{a A}$ & $1.34 \pm 0.02^{a A}$ & $1.32 \pm 0.02^{a A}$ & $1.30 \pm 0.02^{a A}$ \\
& & & & & \\
\multirow{2}{*}{ WPT } & Intermediate liming & $1.31 \pm 0.05^{a A}$ & $1.16 \pm 0.06^{b B}$ & $1.18 \pm 0.06^{b B}$ & $1.20 \pm 0.02^{b B}$ \\
& Hot liming & $1.34 \pm 0.07^{a A}$ & $1.30 \pm 0.09^{a A}$ & $1.30 \pm 0.04^{a A}$ & $1.28 \pm 0.05^{a A}$ \\
\hline
\end{tabular}

Means followed by the same lower case superscript in the same row are not significantly different at $\mathrm{p}<0.05$. Means followed by the same upper case superscript in the same column are not significantly different $\mathrm{p}<0.05$. $\mathrm{n}=3$. 
Alum Effect in Cane Juice Clarification | 71

Table 4: Colour and $\mathrm{pH}$ (mean $\pm \mathrm{SD}$ ) for No Pre-treatment cane juice

\begin{tabular}{lcccc}
\hline \multirow{2}{*}{ Sample } & \multicolumn{2}{c}{ Intermediate Liming } & \multicolumn{2}{c}{ Hot Liming } \\
\cline { 2 - 5 } & Colour (IU) & $\mathrm{pH}$ & Colour (IU) & $\mathrm{pH}$ \\
\hline TMJ & $13271 \pm 396^{b}$ & $5.69 \pm 0.13^{c}$ & $13271 \pm 396^{b}$ & $5.69 \pm 0.14^{c}$ \\
Limed juice & $14917 \pm 456^{a}$ & $7.17 \pm 0.08^{a}$ & $15116 \pm 422^{a}$ & $7.12 \pm 0.19^{a}$ \\
$\mathrm{CJ}_{0}$ & $11337 \pm 114^{c}$ & $6.43 \pm 0.19^{b}$ & $11624 \pm 139^{c}$ & $6.40 \pm 0.11^{b}$ \\
$\mathrm{CJ}_{50}$ & $10636 \pm 131^{d}$ & $6.47 \pm 0.10^{b}$ & $10944 \pm 163^{d}$ & $6.43 \pm 0.12^{b}$ \\
$\mathrm{CJ}_{100}$ & $10397 \pm 143^{d}$ & $6.50 \pm 0.15^{b}$ & $10672 \pm 213^{e}$ & $6.45 \pm 0.18^{b}$ \\
$\mathrm{CJ}_{150}$ & $9905 \pm 180^{f}$ & $6.54 \pm 0.17^{b}$ & $10490 \pm 84^{e}$ & $6.51 \pm 0.15^{b}$ \\
\hline
\end{tabular}

Means in the same column followed by the same superscript are not significantly different at $\mathrm{p}<0.05$. $\mathrm{n}=9 ; \mathrm{CJ}_{0}$, $\mathrm{CJ}_{50}, \mathrm{CJ}_{100}$, and $\mathrm{CJ}_{150}=$ clarified juice after treatment with $0,50,100$ and $150 \mathrm{mg}$ of alum, respectively; IU= ICUMSA Units.

Table 5: Colour and $\mathrm{pH}($ mean $\pm \mathrm{SD})$ in alum and With Pre-treatment cane juice

\begin{tabular}{lcccc}
\hline \multirow{2}{*}{ Sample } & \multicolumn{2}{c}{ Intermediate Liming } & \multicolumn{2}{c}{ Hot Liming } \\
\cline { 2 - 5 } & Colour (IU) & $\mathrm{pH}$ & Colour (IU) & $\mathrm{pH}$ \\
\hline TMJ & $13271 \pm 396^{a}$ & $5.69 \pm 0.14^{d}$ & $13271 \pm 396^{a}$ & $5.69 \pm 0.14^{c}$ \\
AFTINCB & $11041 \pm 544^{c}$ & $5.77 \pm 0.17^{d}$ & $11041 \pm 544^{c}$ & $5.77 \pm 0.17^{c}$ \\
Limed juice & $11965 \pm 624^{b}$ & $7.08 \pm 0.22^{a}$ & $12350 \pm 468^{b}$ & $7.12 \pm 0.12^{a}$ \\
$\mathrm{CJ}_{0}$ & $8925 \pm 675^{d}$ & $6.49 \pm 0.12^{c}$ & $9288 \pm 248^{d}$ & $6.41 \pm 0.09^{b}$ \\
$\mathrm{CJ}_{50}$ & $7799 \pm 569^{e}$ & $6.66 \pm 0.21^{b}$ & $8539 \pm 244^{e}$ & $6.44 \pm 0.13^{b}$ \\
$\mathrm{CJ}_{100}$ & $7672 \pm 569^{e}$ & $6.61 \pm 0.14^{b c}$ & $8186 \pm 420^{e f}$ & $6.47 \pm 0.15^{b}$ \\
$\mathrm{CJ}_{150}$ & $7548 \pm 626^{e}$ & $6.59 \pm 0.16^{b c}$ & $8006 \pm 623^{f}$ & $6.52 \pm 0.13^{b}$ \\
\hline
\end{tabular}

Means in the same column followed by the same superscript are not significantly different at $\mathrm{p}<0.05$. $\mathrm{n}=9 ; \mathrm{CJ}_{0}$, $\mathrm{CJ}_{50}, \mathrm{CJ}_{100}$, and $\mathrm{CJ}_{150}=$ clarified juice after treatment with $0,50,100$ and $150 \mathrm{mg}$ of alum, respectively; IU= ICUMSA Units.

\section{Final mud volumes}

The final mud volumes $\left(\mathrm{MV}_{\infty}\right)$ among the clarified juices in NPT and WPT for both intermediate and hot liming processes are presented in Table 6 . In the NPT intermediate liming, the $\mathrm{MV}_{\infty}$ of the clarified juices at all alum levels were significantly $(\mathrm{p}<0.05)$ different. There was a decrease in the $\mathrm{MV}_{\infty}$ of these juices as thealum level was increased. The highest $M V_{\infty}$ of clarified juice (15.5\%) was recorded in $\mathrm{CJ}_{0}$ while the lowest $\mathrm{MV}_{\infty}$ of clarified juice $(10.5 \%)$ was recorded in $\mathrm{CJ}_{150}$. In the NPT hot liming, a similar trend of a decrease in theMV $\mathrm{V}_{\infty}$ of clarified juiceswith the increasing alum level was observed. The highest $\mathrm{MV}_{\infty}$ of clarified juice $(18.2 \%)$ in $\mathrm{CJ}_{0}$ was significantly $(\mathrm{p}<0.05)$ different from the rest of the $\mathrm{MV}_{\infty}$ of the clarified juices. Generally, higher $\mathrm{MV}_{\infty}$ ofclarified juiceswere observed in NPT hot liming than in NPT intermediate liming for each alum level. In the WPT intermediate liming, the $\mathrm{MV}_{\infty}$ of the clarified juice from all the alum treatments were significantly different $(\mathrm{p}<0.05)$. The lowest $\mathrm{MV}_{\infty}$ $(10.8 \%)$ was recorded in $\mathrm{CJ}_{150}$ and was significantly different from $\mathrm{CJ}_{0}$. In the WPT hot liming, $\mathrm{CJ}_{0} \mathrm{MV}_{\infty}$ was significantly high $(\mathrm{p}<0.05)$. The lowest $\mathrm{MV}_{\infty}$ of $11.6 \%$ in $\mathrm{CJ}_{150}$ was not significantly $(\mathrm{p}<0.05)$ different from $12.0 \%$ in $\mathrm{CJ}_{100}$. The larger mud volumes in hot liming explain the slow initial settling rates compared to intermediate liming. A similar observation was made by Eggleston, Monge, and Pepperman (2002) when comparing settling rates in cold and intermediate liming processes. 
$72 \mid$ Kimatu et al.

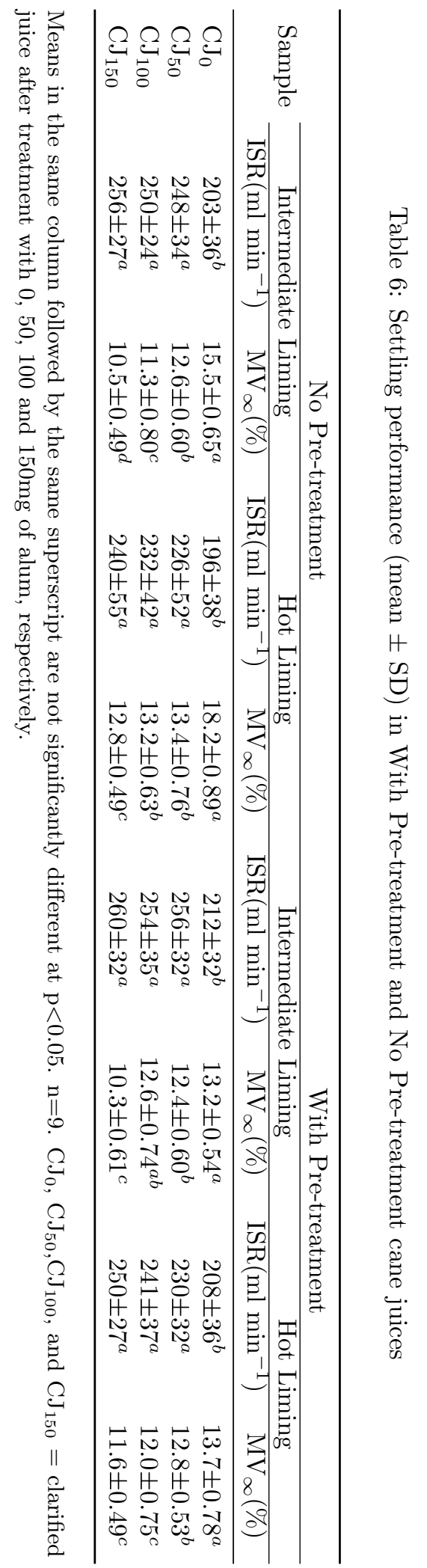

IJFS | April 2015 | Volume 4 |pages 61-77 
Alum Effect in Cane Juice Clarification |73
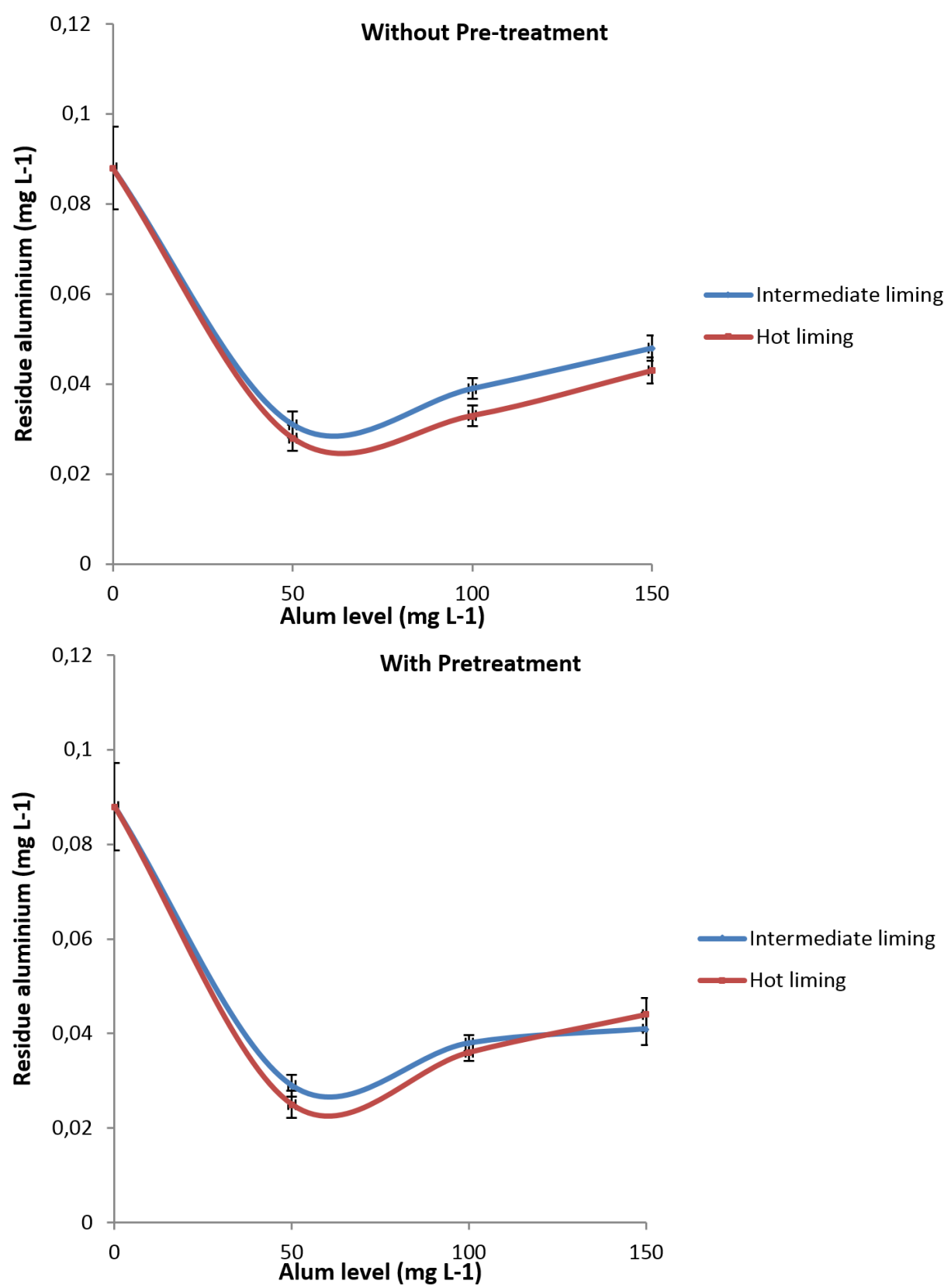

Figure 2: Concentration of residual aluminium $\left(\mathrm{mg} \mathrm{L}^{-1}\right)$ in clarified juice 
74 | Kimatu et al.

Table 7: Turbidity (IU) (mean $\pm \mathrm{SD}$ ) in No Pre-treatment and With Pre-treatment cane juices

\begin{tabular}{lcccc}
\hline & \multicolumn{2}{c}{ No Pre-treatment } & \multicolumn{2}{c}{ With Pre-treatment } \\
\cline { 2 - 5 } Sample & Intermediate Liming & Hot Liming & Intermediate Liming & Hot Liming \\
\hline MJ & $54685 \pm 4498^{a}$ & $54685 \pm 4498^{a}$ & $54685 \pm 4498^{a}$ & $54685 \pm 4498^{a}$ \\
$\mathrm{CJ}_{0}$ & $4594 \pm 359^{b}$ & $4958 \pm 234^{b}$ & $3719 \pm 461^{b}$ & $3831 \pm 305^{b}$ \\
$\mathrm{CJ}_{50}$ & $2618 \pm 377^{c}$ & $2968 \pm 429^{c}$ & $1459 \pm 234^{c}$ & $1870 \pm 301^{c}$ \\
$\mathrm{CJ}_{100}$ & $2389 \pm 342^{c}$ & $2855 \pm 285^{c}$ & $1187 \pm 209^{c}$ & $1380 \pm 227^{c}$ \\
$\mathrm{CJ}_{150}$ & $2172 \pm 339^{c}$ & $2634 \pm 404^{c}$ & $1024 \pm 222^{c}$ & $1272 \pm 288^{c}$ \\
\hline
\end{tabular}

Means in the same column followed by the same superscript are not significantly different at $\mathrm{p}<0.05$. $\mathrm{n}=9$. CJ $\mathrm{CJ}_{50}, \mathrm{CJ}_{100}$, and $\mathrm{CJ}_{150}=$ clarified juice after treatment with $0,50,100$ and $150 \mathrm{mg}$ of alum, respectively.

\section{Turbidity measurement}

Turbidity is an optical property of a liquid that describes the clarity or haziness of the liquid. It is not colour related, but rather relates to the loss of transparency due to the effect of suspended particulates, colloidal material, or both. The ICUMSA turbidity measurement is a spectrophotometric technique that measures absorbance at $420 \mathrm{~nm}$ and is an indication of suspended matter in cane juice (Maseko, Singh, \& Motsa, 2011). The removal of turbidity is indicative of the removal of these components (Hamerski, da Silva, Corazza, Ndiaye, \& de Aquino, 2012). To determine the extent of turbidity removal after clarification of the various treatment cane juices, turbidity values of the MJ and the clarified juices were measured and the results are summarised in Table 7. In the NPT intermediate liming, turbidity was significantly $(\mathrm{p}<0.05)$ removed on clarification of the MJ. The highest turbidity removal of $96 \%$ in $\mathrm{CJ}_{150}$ was not significantly different from a turbidity removal of $95.6 \%$ in $\mathrm{CJ}_{100}$ and $95.2 \%$ in $\mathrm{CJ}_{50}$. The lowest turbidity removal of $91.6 \%$ was in $\mathrm{CJ}_{0}$. In the NPT hot liming, turbidity was significantly $(\mathrm{p}<0.05)$ removed from MJ on clarification. Turbidity removed in $\mathrm{CJ}_{0}(90.9 \%)$ was significantly $(\mathrm{p}<0.05)$ lower than $94.6 \%, 94.8 \%$ and $95.2 \%$ removed in $\mathrm{CJ}_{50}$ and $\mathrm{CJ}_{100}$ and $\mathrm{WCJ}_{150}$, respectively. In the WPT intermediate liming, turbidity removed in $\mathrm{CJ}_{50}, \mathrm{CJ}_{100}$ and $\mathrm{CJ}_{150}$ was not significantly $(\mathrm{p}<0.05)$ different. However, turbidity removed in $\mathrm{CJ}_{0}$ was significantly $(\mathrm{p}<0.05)$ lower. In the WPT hot liming process, turbidity removed in $\mathrm{CJ}_{0}(93 \%)$ was significantly lower than turbidity removed in $\mathrm{CJ}_{50}, \mathrm{CJ}_{100}$ and $\mathrm{CJ}_{150}$. It is evident that the WPT clarified juices had better turbidity removal than the NPT clarified juices. This could be partly due to the faster settling of the larger flocs that are formed in preheating of the $50 \%$ of the MJ and partly due to the presence of the resulting complex positively charged ions from alum, which adsorb to the negative turbidity particles thus neutralizing their charge. This could also be seen in the initial settling rates where higher ISRs were observed in the WPT than in the NPT cane juices (Table 6). This was in agreement with studies by Eggleston, Monge, and Pepperman (2002) and de Armas et al. (1999) who reported formation of larger flocs and faster settling rates leading to higher turbidity removal upon preheating of the mixed cane juice before liming. These results therefore suggest that incorporating alum in WPT intermediate liming has a great potential for turbidity removal in cane juice clarification.

\subsection{Residual aluminium ions}

To determine the aluminium carryover in the clarified juice, residual aluminium concentration in the clarified juice was quantified and compared to the aluminium concentration in the untreated cane juice. The results are summarised in Figure 2. In all the clarified juices, for both WPT and NPT, the residual aluminium concentration was significantly lower $(\mathrm{p}<0.05)$ than in the untreated juice. This showed that even with the cane juice treatment with alum, the clarification process was able to remove aluminium from the cane juice to levels lower than the natural aluminium concentration in the untreated cane juice. This was in agreement with studies by Anon $(2005,2006)$ who noted no 
aluminium carryover in the clarified juice when using polyaluminium coagulants in conjunction with normal lime clarification.

\section{Conclusions}

Incorporation of alum in the clarification of cane juice showed improvements in colour and turbidity removal with the preheating and incubation of the MJ in WPT resulting in higher colour and turbidity removal than in NPT. Similarly, lower sucrose losses were observed in intermediate lime clarification of WPT cane juice, strongly suggesting that alum could be used by sugar processors to improve clarification and reduce sucrose losses. Higher ISRs and compact $M V_{\infty}$ were found in the alum treated cane juices than in the control juice in both NPT and WPT. This observation could be an important step in reducing the possibility of mud carryover to the evaporator station and in lowering the burden of mud volume in the mud filter station. This study indicates the potential of the applicability of incorporating alum in intermediate lime clarification of WPT without the risk of aluminum carryover in the clarified juice.

\section{Acknowledgements}

The authors are grateful to the National Commission for Science, Technology and Innovation (NACOSTI) and the Regional Forum for Agriculture (RUFORUM) for their financial support. We are also grateful to Mumias Sugar Company for allowing us to use their facility for sample collection and laying down of the experiments. Lastly we thank the Department of Dairy and Food Science and Technology - Egerton University, Department of Food Science and Post harvest Technology - Jomo Kenyatta University of Agriculture and Technology and Kenya Agricultural Research Institute Njoro for allowing us to use their laboratory facilities for various analyses.

\section{References}

Anon. (2005). Characterization and improvement of sugarcane and sugar beet process units. Sugar Process Research Institute (SPRI) Annual Report 1 p.1. Retrieved from http:// www . ars . usda . gov / research / projects / projects . htm ? ACCN_NO $=407457 \%$ 5C \& showpars $=$ true $\% 5 \mathrm{C} \& f y=2005$

Anon. (2006). Characterization and improvement of sugarcane and sugar beet process units. Sugar Process Research Institute (SPRI) Annual Report 1 p.1. Retrieved from http:// www . ars . usda . gov / research / projects / projects . htm ? ACCN_NO $=407457 \%$ 5C \& showpars $=$ true $\% 5 \mathrm{C} \& \mathrm{fy}=2006$

Davis, S. B. (2001). The chemistry of colour removal: a processing perspective. In Annual congress of south african sugar technologists association (Vol. 75, pp. 328-336). KwaZuluNatal: SASTA. Durban.

de Armas, R., Martinez, M., Vicente, C., \& Legaz, M. E. (1999). Free and conjugated polyamines and phenols in raw and alkalineclarified sugarcane juices. Journal of Agricultural and Food Chemistry, 47(8), 3086-3092. doi:10.1021/jf980715+

Degremont, P. (1991). Water treatment handbook. (6th ed. vol. 2). Rueil-Malmaison Cedex. Paris: Lavoisier Publishing.

Eggleston, G. (2000). Hot and cold lime clarification in raw sugar manufacture i: juice quality differences. International Sugar Journal, 102(1220), 406-416.

Eggleston, G. \& Amorim, H. (2006). Reasons for the chemical destruction of sugars during the processing of sugar cane for raw sugar and fuel alcohol production. International Sugar Journal, 108(1289), 271-282.

Eggleston, G., Clarke, M. A., \& Pepperman, A. B. (1999). Mixed juice clarification of fresh and deteriorated sugarcane. International Sugar Journal, 101, 296-300.

Eggleston, G. \& Monge, A. (2005). Minimization of seasonal sucrose losses across robert's-type evaporators in raw sugar manufacture by ph optimization. Journal of Agricultural and Food Chemistry, 53(16), 6332-6339. doi:10. 1021/jf058019e

Eggleston, G., Monge, A., \& Ogier, B. E. (2002). Sugarcane factory performance of cold, intermediate, and hot lime clarification processes. Journal of Food Processing and Preservation, $26(6), 433-454$. 
Eggleston, G., Monge, A., \& Pepperman, A. (2002). Preheating and incubation of cane juice prior to liming: a comparison of intermediate and cold lime clarification. Journal of Agricultural and Food Chemistry, 50(3), 484-490. doi:10.1021/jf010999p

Eggleston, G., Vercellotti, J. R., Edye, L. A., \& Clarke, M. A. (1996). Effects of salts on the initial thermal degradation of concentrated aqueous solutions of sucrose. Journal of Carbohydrate Chemistry, 15(1), 81-94. doi:10 . 1080/07328309608005427

Eggleston, G., Grisham, M., \& Antoine, A. (2010). Clarification properties of trash and stalk tissues from sugar cane. Journal of Agricultural and Food Chemistry, 58(1), 366-373. doi:10. 1021/jf903093q

Eggleston, G., Legendre, D., Pontif, K., \& Gober, J. (2014). Improved control of sucrose losses and clarified juice turbidity with lime saccharate in hot lime clarification of sugarcane juice and other comparisons with milk of lime. Journal of Food Processing and Preservation, 38(1), 311-325. doi:10.1111/j.17454549.2012.00779.x

Godshall, M. A., Clarke, M. A., \& Dooley, C. D. (1991). Starch: process problems and analytical developments. In Proceedings of the sugar processing research conference (pp. 244-264). San Francisco, California (USA).

Godshall, M. A., Mckee, M., Triche, R., \& Moore, S. (2006). Studies on the action of polyaluminum coagulants. In Proc. issct processing workshop, june 1. lod-cook conference center, lsu. Baton Rouge, Louisiana.

Hamerski, F., da Silva, V. R., Corazza, M. L., Ndiaye, P. M., \& de Aquino, A. D. (2012). Assessment of variables effects on sugar cane juice clarification by carbonation process. International Journal of Food Science and Technology, 47(2), 422-428. doi:10.1111/j. 1365-2621.2011.02857.x

ICUMSA. (2002). Methods book. international commission for uniform methods of sugar analysis. Norwich Research Park, Conley, England. Method GS7/4/8-23.

ICUMSA. (2005). Methods book. international commission for uniform methods of sugar analysis. Norwich Research Park, Conley, England. Method GS2/3-10.
Jiang, J. \& Graham, N. J. D. (1998). Prepolymerised inorganic coagulants and phosphorus removal by coagulation - a review. Water SA, 24(3), 237-244.

Lionnet, G. R. \& Ravn, A. (1976). Flocculant assessment using a portable batch settling kit. In Annual congress of south african sugar technologists association (pp. 177178). KwaZulu-Natal: SASTA. Durban.

Maseko, Q., Singh, R., \& Motsa, N. (2011). Steps taken to improve refined sugar turbidity at the pangola sugar refinery. In Annual congress of south african sugar technologists association (pp. 499-509). KwaZulu-Natal: SASTA. Durban.

Muisa, N., Hoko, Z., \& Chifamba, P. (2011). Impacts of alum residues from morton jaffray water works on water quality and fish, harare, zimbabwe. Physics and Chemistry of the Earth, 36(14-15), 853-864. 11th WaterNet/WARFSA/GWP-SA Annual Symposium, Victoria Falls, ZIMBABWE, OCT 27-29, 2010. doi:10.1016/j.pce. 2011. 07.047

Nguyen, D. M. T. \& Doherty, W. O. S. (2012a). Optimisation of process parameters for the degradation of caffeic acid in sugar solutions. International Journal of Food Science and Technology, 47(12), 2477-2486.

Nguyen, D. M. T. \& Doherty, W. O. S. (2012b). Optimisation of process parameters for the removal of hydroxycinnamic acids in sugar solutions. Proceedings of the Australian Society of Sugar Cane Technologists, 34. Retrieved from http://www.eprints.qut.edu. us $/ 50485 / 2 / 50485$.pdf

Ravina, L. \& Moramarco, N. (1993). Everything you want to know about coagulation \& flocculation. Zeta-Meter Inc, 19-24. Retrieved from http://www.zeta-meter.com/coag.pdf

Rein, P. W. \& Bento, L. S. M. (2006). Direct production of white sugar. In Proc. issct processing workshop, june 1. lod-cook conference center, lsu. Baton Rouge, Louisiana.

SAS. (2002-2003). User's guide. SAS Institute, Cary, North Carolina, USA. Retrieved from http : / / support. sas . com / documentation / cdl / en / statug / 63962 / HTML / default / viewer.htm 
Saska, M., Zossi, B. S., \& Liu, H. (2010a). Colour behaviour in cane juice clarification by defecation, sulfitation and carbonation. In International society of sugar cane technologists (Vol. 27, pp. 1-14). Quartre-Bornes: ISSCT. Saska, M., Zossi, B. S., \& Liu, H. (2010b). Removal of colour in sugar cane juice clarification by defecation, sulfitation and carbonation. International Sugar Journal, 112(1337), 258+.

Schaffler, K. J., Muzzell, D. J., \& Schorn, P. M. (1985). An evaluation of sucrose inversion and monosaccharide degradation across evaporation at darnall mill. In Annual congress of south african sugar technologists association (Vol. 59, pp. 73-78). KwaZuluNatal: SASTA. Durban.

Schoonees-Muir, B. M. \& Gwegwe, B. M. M. (2008). The use of polyaluminium coagulants for the removal of colour during clarification. In Annual congress of south african sugar technologists association (Vol. 59, pp. 160164). KwaZulu-Natal: SASTA. Durban.

SPRI. (2006). Reduction of lime usage with cationic aluminium coagulants in juice clarification. Sugar Processing Research Institute. Technical report. (industry confidential). Retrieved from http://www.spriinc. org/reportspg.html

Zouboulis, A. I. \& Traskas, G. (2005). Comparable evaluation of various commercially available aluminium-based coagulants for the treatment of surface water and for the post-treatment of urban wastewater. Journal of Chemical Technology and Biotechnology, 80(10), 1136-1147. doi:10.1002/jctb.1300 